This is an open access article distributed under the terms of the Creative Commons BY-NC-ND Licence

\title{
Mitochondrial respiration after combined action of dehydration and low temperature in pea seedlings
}

\author{
I.P. GENEROZOVA*, P.A. BUTSANETS, and A.G. SHUGAEV \\ Timiryazev Institute of Plant Physiology, Russian Academy of Sciences, Moscow, 127276 Russia
}

\begin{abstract}
The impact of the individual and combined action of dehydration and low temperature on the respiratory activity of mitochondria isolated from epicotyls of pea (Pisum sativum L.) seedlings was investigated. These organelles were isolated immediately after the treatments and after two and three days of recovery. After the treatments, the capacity of the energy-producing cytochrome pathway (CP) of mitochondrial oxidation decreased, while the capacity of the nonphosphorylating alternative respiratory pathway (AP) catalyzed by a $\mathrm{CN}$-resistant oxidase was elevated. After returning the seedlings to normal growing conditions, a gradual recovery of the respiratory activity of mitochondria was observed due to the inactivation of the AP and an elevation of the activity of the CP. The dehydration was a strong stress factor and led to a more significant disturbance of mitochondrial functioning than low temperature, and the complete recovery of the respiratory activity was observed only after the combined action of these stress factors. The post-stress reactivation of malate rather than succinate oxidation required a longer maintenance of seedlings under the control conditions.
\end{abstract}

Additional key words: alternative oxidase, cytochrome pathway, malate, Pisum sativum, succinate, water deficit.

\section{Introduction}

It is known that mitochondria in eukaryotic cells are actively involved in the integration and regulation of cell metabolism and are highly sensitive to different environmental stresses. In particular, it has been shown that significant disturbances in mitochondrial function occur under drought. In this case, an inhibition of phosphorylating oxidation and cytochrome electron transport chain (ETC) was observed (Atkin and Macherel 2008, Generozova et al. 2009, Van Aken et al. 2009). As a rule, the different types of abiotic stresses lead to the same defence responses in mitochondria. These responses are associated with the maintenance of both their metabolic activity and a rather low accumulation of reactive oxygen species (ROS). It is especially important to consider that mitochondrial ETC complexes may be a source of ROS (Huang et al. 2016, Belt et al. 2017). The process of overcoming oxidative stress is often triggered by a proper activation of alternative oxidoreductases such as an alternative $\mathrm{CN}$-resistant oxidase (AOX) and rotenone-insensitive $\mathrm{NAD}(\mathrm{P}) \mathrm{H}$-dehydrogenases. There are good reasons to believe that the major function of AOX and other alternative pathways of uncoupled electron transport in plant mitochondria are to maintain the ETC activity after stress-induced retardation of cytochrome electron transport and to prevent excess ROS generation (Clifton et al. 2005, Van Aken et al. 2009, Vanlerberghe 2013). The mitochondrial respiratory chain function and the ability of these organelles to recover their respiratory activity after stress conditions are thought to be essential criteria for plant tolerance to unfavourable factors of their environment (Clifton et al. 2005, Stupnikova et al. 2006, Atkin and Macherel 2008, Vanlerberghe 2013). However, at present, the data concerning plant mitochondrial response to the combined action of several stress factors and the regulation of the process responsible for recovering their respiratory activity after stress removal are extremely limited.

Submitted 30 October 2017, last revision 11 May 2018, accepted 21 May 2018.

Abbreviations: AOX - alternative oxidase; AP - alternative pathway of mitochondrial oxidation; CP - cytochrome pathway; ETC electron transport chain; LSD - ??; MDA - malondialdehyde; RC - respiratory control; ROS - reactive oxygen species; RR - residual respiration; SHAM - salicylhydroxamic acid; TBA - thiobarbituric acid.

Acknowledgements: We are grateful to Dr I.M. Andreev for reading the manuscript and their comments

* Corresponding author; e-mail: igenerozova@mail.ru 
The cross-adaptation concept based on studies of plant tolerance to different abiotic stresses individually acting implies the existence of common adaption systems responsible for overcoming stress in plants (Kuznetsov 2001). Recently, studies of combined effects, i.e., simultaneous or sequential action of different abiotic stresses often occurring under natural conditions, have been exhibited a clear progress. For example, a great attention has been given to a combined action of drought and high temperature (Zandalinas et al. 2018). The data outlined here as well as in other reports indicate two features of plant responses to combined action of several stresses. Firstly, this response significantly differs from the action of one stress factor, and secondly, a combined action of several stresses exerts often a more negative action on plants than each of them (Rizsky et al. 2004, Giraud et al. 2008, Mittler 2008, Rasmussen et al. 2013, Rivero et al. 2014, Prasch and Sonnewald 2015, Zandalinas et al. 2018). However, some combinations of factors, for example, elevated $\mathrm{CO}_{2}$ and ozon concentrations can have a more favorable effect on plants compared with each of the factors applied individually (Ainsworth et al. 2008). It is probable that the combined action of several factors is capable to elevate the adaptive abilities of plants. Recent reports showed that combined

\section{Material and methods}

In the present work, etiolated pea (Pisum sativum L., cv. Flora-2) seedlings were used. Pea seeds were washed with $0.01 \%(\mathrm{~m} / \mathrm{v}) \mathrm{KMnO}_{4}$ solution and germinated in the dark on filter paper wet with distilled water at $24{ }^{\circ} \mathrm{C}$. After two days of growth, one group of seedlings was grown further under the same conditions for $3-4 \mathrm{~d}$ (control), and the other group was subjected to the action of a lower temperature $\left(15^{\circ} \mathrm{C}\right)$ for one day or placed on dry filter paper and left at 24 or $15^{\circ} \mathrm{C}$ for one day. Plant samples (epicotyls) were taken immediately after the application of these stress factors and after two and three days of recovery under control conditions.

Mitochondria were isolated by a previously described method (Generozova et al. 2009). Briefly, epicotyls (15 - $20 \mathrm{~g})$ were separated from seedlings, placed into a blender filled with a medium (volume ratio 1:2) and rapidly homogenized. A homogenization medium contained $0.4 \mathrm{M}$ sucrose, $5 \mathrm{mM} \mathrm{Na} \mathrm{NaDTA}_{2} 20 \mathrm{mM}$ potassium-phosphate buffer ( $\mathrm{pH} 8.0), 10 \mathrm{mM} \mathrm{KCl}, 2 \mathrm{mM}$ dithiothreitol, and $0.1 \%(\mathrm{~m} / \mathrm{v})$ fatty-acid-free bovine serum albumin (BSA). The homogenate was filtered through calico and centrifuged at $25000 \mathrm{~g}$ for $5 \mathrm{~min}$. The pellet obtained was suspended in $8 \mathrm{~cm}^{3}$ of a washing medium containing $0.4 \mathrm{M}$ sucrose, $20 \mathrm{mM}$ potassiumphosphate buffer ( $\mathrm{pH} 7.4$ ), $5 \mathrm{mM} \mathrm{Na} 2$ EDTA, $10 \mathrm{mM} \mathrm{KCl}$ and $0.2 \% \mathrm{BSA}$ and then centrifuged at $3000 \mathrm{~g}$ for $3 \mathrm{~min}$. The supernatant was centrifuged at $11000 \mathrm{~g}$ for $10 \mathrm{~min}$ to precipitate mitochondria. The pellet was suspended in stresses induce specific responses including the induction of the expression of a number of specific proteins (Rizsky et al. 2004, Giraud et al. 2008, Rivero et al. 2014, Prasch and Sonnewald 2015).

In our work, we attempted to test the hypothesis that a combined action of two factors, drought and a moderately low temperature, can be less stressful than the action of them individually. Such a combination often occurs in nature, for example, in spring after small-snow winter.

When planning these experiments, we chose the factors that do not cause the death of plants, and one of them exerts a less severe action (low temperature) than the other (drought). A similar approach to proper selection of environmental stress factors was used by Bandurska et al. (2013) to study the action UV radiation and drought. Our previous investigation showed that dehydrating and moderately chilling etiolated pea seedlings show a marked change in the fatty acid composition of their mitochondrial membranes (Zhigacheva et al. 2011). The purpose of the present work was to investigate the respiratory activity of mitochondria isolated from pea epicotyls after dehydration and moderately low temperature individually or in combination as well as after recovery under the control conditions.
$2-3 \mathrm{~cm}^{3}$ of the medium containing $0.4 \mathrm{M}$ sucrose, $20 \mathrm{mM}$ potassium-phosphate buffer ( $\mathrm{pH} 7.4$ ), and $0.1 \%$ BSA and centrifuged again to precipitate the organelles. A final mitochondrial suspension containing $6 \mathrm{mg} \mathrm{cm}^{-3}$ of total protein was kept on ice prior to use.

Oxygen uptake by mitochondria was measured amperometrically using the electrode designed by Sholts and Ostrovsky (1975). A reaction medium $\left(1 \mathrm{~cm}^{3}\right)$ contained $0.4 \mathrm{M}$ sucrose, $20 \mathrm{mM}$ potassium-phosphate buffer ( $\mathrm{pH} 7.4$ ), and $0.1 \%$ BSA. To determine the rate of oxygen uptake by the mitochondria in state 3 , the medium was supplemented with $10 \mathrm{mM}$ malate or succinate in the presence of $10 \mathrm{mM}$ glutamate, to remove oxaloacetate, and $200 \mu \mathrm{M}$ ADP. The respiration rate and the respiratory control (RC) ratio were calculated according to the method of Chance and Williams (1956; $\mathrm{RC}=$ ratio of the oxygen uptake rate of mitochondria in the presence of both substrate and ADP to the rate in the presence of substrate but the absence of ADP). The content of total mitochondrial protein was determined by the method of Lowry et al. (1951) using BSA as a standard.

The respiratory capacity of different mitochondrial ETC oxidation pathways was determined by analyses with inhibitors: $2 \mathrm{mM} \mathrm{KCN}$ as an inhibitor of the cytochrome pathway (CP) and $2 \mathrm{mM}$ salicylhydroxamic acid (SHAM) as an inhibitor of an alternative, cyanideresistant pathway (AP). The $\mathrm{O}_{2}$ uptake by mitochondria 
in state 3 in the absence of any inhibitor presented the total respiration, and that in the presence of both $\mathrm{KCN}$ and SHAM showed the residual respiration (RR). The respiration rate through the $\mathrm{CP}$ was determined by measuring the extent of its inhibition in state 3 by $\mathrm{KCN}$ in the presence of SHAM. The maximum activity (or capacity) of the AP was estimated by the extent of its inhibition by SHAM in the presence of KCN (McDonald et al. 2002). The optimal concentrations of the inhibitors were selected in preliminary experiments. In preliminary experiments, we also showed that the addition of dithiothreitol $(2 \mathrm{mM})$ and pyruvate $(5 \mathrm{mM})$ to the reaction medium or to all media during the release of mitochondria was not accompanied by a marked activation of AOX and an increase in AP capacity.

The water deficit (WD) in pea epicotyl tissues was determined according to the formula of Schmitt and Dizengremel (1989): WD [\%] = [(water saturated mass - fresh mass $) /($ water saturated mass - dry mass $)] \times 100$. The water saturated mass of epicotyls was determined according to the method of Garnier at al (2001) with some modifications. Epicotyls (7 - 10 of each variant) were placed in a chamber on moistened filter paper for $24 \mathrm{~h}$ to obtain water saturated mass. Dry mass was determined after drying at $105{ }^{\circ} \mathrm{C}$ for $0.5 \mathrm{~h}$ and then at $65^{\circ} \mathrm{C}$ for about $72 \mathrm{~h}$.

The content of malondialdehyde (MDA) in epicotyl tissues was determined spectrometrically using the thiobarbituric acid method according to Hodges et al. (1999).

In tables and figures, means and standard deviations obtained from the data of 3 - 5 independent experiments are shown. For the epicotyl length, the significance of differences was estimated using the Student $t$-test at $\alpha=0.05$. Different letters indicate significant differences at $P<0.05$ according to the LSD test.

\section{Results and discussion}

Mitochondrial respiration in control pea seedlings after 3 - $5 \mathrm{~d}$ of growth was high and in a good accordance with literature data (Havkin 1977). However, on the sixth day

of growth, both the rate of substrate oxidation by mitochondria and the RC value slightly decreased (Table 1, Fig. 1). It is possible that it was caused by the

Table 1. Total respiration rate, cytochrome respiration pathway (CP), alternative respiration pathway (AP), and residual respiration (RR) $\left[\mathrm{ng}(\mathrm{O}) \mathrm{mg}^{-1}\right.$ (protein) $\mathrm{min}^{-1}$ ] of mitochondria isolated from epicotyls of 2-d-old pea seedlings subjected to a low temperature, dehydration, or the combined stress for $1 \mathrm{~d}$ and in the course of post-stressed recovery under control conditions. Means \pm SDs, $n=3$. Different letters within the same row indicate significant differences at $P<0.05$ according to the LSD test.

\begin{tabular}{|c|c|c|c|c|c|}
\hline Parameter/time & Pathways & Control & Low temperature & Dehydration & Combined stress \\
\hline \multirow[t]{4}{*}{ Malate/ immediately } & $\mathrm{CP}$ & $168 \pm 21 \mathrm{a}$ & $113 \pm 14 b$ & $46 \pm 11 \mathrm{c}$ & $42 \pm 9 c$ \\
\hline & AP & $3 \pm 1 \mathrm{a}$ & $33 \pm 7 b$ & $37 \pm 3 b$ & $31 \pm 6 b$ \\
\hline & $\mathrm{RR}$ & $17 \pm 5 \mathrm{a}$ & $22 \pm 4 a$ & $37 \pm 5 b$ & $30 \pm 8 \mathrm{a}$ \\
\hline & total & $188 \pm 24 \mathrm{a}$ & $168 \pm 18 \mathrm{a}$ & $120 \pm 21 b$ & $103 \pm 15 b$ \\
\hline \multirow[t]{4}{*}{ Succinate/immediately } & $\mathrm{CP}$ & $199 \pm 20 a$ & $179 \pm 19 a$ & $51 \pm 14 b$ & $27 \pm 8 \mathrm{c}$ \\
\hline & AP & $16 \pm 4 \mathrm{a}$ & $32 \pm 9 b$ & $17 \pm 4 \mathrm{a}$ & $27 \pm 6 b$ \\
\hline & $\mathrm{RR}$ & $21 \pm 7 \mathrm{a}$ & $8 \pm 2 b$ & $34 \pm 8 c$ & $43 \pm 9 c$ \\
\hline & total & $236 \pm 22 \mathrm{a}$ & $219 \pm 21 \mathrm{a}$ & $102 \pm 19 b$ & $97 \pm 18 b$ \\
\hline \multirow[t]{4}{*}{ Malate/2-d recovery } & $\mathrm{CP}$ & $288 \pm 23 a$ & $184 \pm 18 b$ & $84 \pm 21 \mathrm{c}$ & $83 \pm 18 c$ \\
\hline & AP & $8 \pm 2 a$ & $16 \pm 3 b$ & $5 \pm 1 \mathrm{a}$ & $11 \pm 3 b$ \\
\hline & $\mathrm{RR}$ & $8 \pm 2 a$ & $8 \pm 3 a$ & $<1 \mathrm{~b}$ & $4 \pm 1 \mathrm{a}$ \\
\hline & total & $305 \pm 22 a$ & $208 \pm 17 b$ & $89 \pm 12 c$ & $98 \pm 11 \mathrm{c}$ \\
\hline \multirow[t]{4}{*}{ Succinate/ 2-d recovery } & $\mathrm{CP}$ & $231 \pm 21 \mathrm{a}$ & $168 \pm 16 b$ & $110 \pm 11 \mathrm{c}$ & $212 \pm 14 \mathrm{a}$ \\
\hline & AP & $3 \pm 1 \mathrm{a}$ & $24 \pm 3 b$ & $8 \pm 1 \mathrm{c}$ & $20 \pm 4 b$ \\
\hline & $\mathrm{RR}$ & $23 \pm 12 \mathrm{a}$ & $8 \pm 3 b$ & $5 \pm 2 b$ & $8 \pm 1 b$ \\
\hline & total & $257 \pm 11 \mathrm{a}$ & $200 \pm 19 b$ & $123 \pm 18 \mathrm{c}$ & $240 \pm 19 a$ \\
\hline \multirow[t]{4}{*}{ Malate/3-d recovery } & $\mathrm{CP}$ & $212 \pm 11 \mathrm{a}$ & $90 \pm 9 b$ & $113 \pm 18 \mathrm{c}$ & $236 \pm 21 \mathrm{a}$ \\
\hline & AP & $30 \pm 7 a$ & $10 \pm 3 b$ & $22 \pm 6 a$ & $24 \pm 5 \mathrm{a}$ \\
\hline & $\mathrm{RR}$ & $19 \pm 1 \mathrm{a}$ & $9 \pm 2 b$ & $21 \pm 9 \mathrm{a}$ & $21 \pm 3 a$ \\
\hline & total & $261 \pm 18 \mathrm{a}$ & $109 \pm 13 b$ & $156 \pm 23 c$ & $281 \pm 22 \mathrm{a}$ \\
\hline \multirow[t]{4}{*}{ Succinate/3-d recovery } & $\mathrm{CP}$ & $156 \pm 14 \mathrm{a}$ & $115 \pm 10 \mathrm{~b}$ & $61 \pm 8 c$ & $318 \pm 12 d$ \\
\hline & $\mathrm{AP}$ & $9 \pm 2 a$ & $7 \pm 2 a$ & $17 \pm 2 b$ & $30 \pm 8 \mathrm{c}$ \\
\hline & $\mathrm{RR}$ & $13 \pm 3 a$ & $7 \pm 1 b$ & $7 \pm 2 b$ & $18 \pm 3 a$ \\
\hline & total & $178 \pm 15 \mathrm{a}$ & $129 \pm 14 b$ & $85 \pm 11 \mathrm{c}$ & $366 \pm 25 d$ \\
\hline
\end{tabular}


absence of light, a phenomenon that has been also reported in the literature (Hill et al. 1992, Møller and Gardestroöm 2007). Nevertheless, the isolation technique used during the selected periods of pea seedling growth allowed us to obtain high-quality mitochondria from the epicotyls of the control pea seedlings, i.e., ones that met all the integrity-related criteria. In particular, they possessed intact membranes and exhibited high oxidizing and phosphorylating activities indicating close coupling between oxidation and phosphorylation as determined by high RC values during the oxidation of tricarboxylic acid cycle substrates (Generozova et al. 2009).

Immediately after the dehydration and/or low temperature treatments, the rate of active or phosphorylating oxidation of substrates by mitochondria in state 3 , i.e., in the presence of ADP, sharply decreased (Table 1). Further, changes in the capacity of different mitochondrial oxidation pathways were observed. The capacity of the CP, coupled with ATP synthesis, was dramatically reduced. However, the maximal capacity of the non-phosphorylating AOX pathway, which is CN-resistant and sensitive to SHAM, significantly increased (Table 1) as well as the RR. Although the nature of the RR remains unclear, it was shown that it may be considerable under abiotic stresses including plant dehydration (Shugaeva et al. 2007, Song et al. 2009). As expected, the RC value sharply dropped providing evidence for the disruption of the mechanism underlying the regulation of mitochondrial respiration by the adenylate cell system (Fig. 1).

In addition to the common characteristic changes in mitochondria function mentioned above, it appeared that each stress exerted a specific effect on respiratory activity. Thus, the rate of oxidation of the substrates, succinate and malate, in state 3 appeared to be to the greatest extent suppressed after the combined action of both treatments on the seedlings. The capacity of the $\mathrm{CP}$ decreased considerably under dehydration and combined stresses (Table 1). In these experiments, a considerable elevation in the capacity of the AP and a strong decrease in the RC value (Fig. 1) were observed.

The growth of treated seedlings was observed after 2-d recovery in control conditions. During this period, significant changes in ETC operation occurred. In particular, after the combined stress, an increase in the CP capacity was observed and the rate of succinate oxidation in the state 3 was practically recovered (Table 1 ). The RC value was elevated indicating the recovery of normal regulation of the mitochondrial respiration by the adenylate cell system and a tight coupling between oxidation and phosphorylation (Fig. 1). This is supported by a drop in the capacity of the non-phosphorylating AP oxidation and a decrease in the rate of RR. These last changes appeared to be particularly pronounced after the low temperature and dehydration (Table 1).

The significant differences in the sensitivity of mitochondrial oxidation of succinate and malate supplying electrons to different sites of the ETC were observed during the post-stressed recovery. The rate of succinate oxidation in mitochondria isolated from the control seedlings growing in the period between the third and fifth day did not change. But this rate was dramatically elevated after dehydration and especially after the combined stress. In contrast, the rate of malate oxidation in state 3 mitochondria isolated from the control plants in the same time period increased almost twofold. However, in the course of seedlings recovering after cold, it was elevated to only a small extent, whereas after dehydration, it even decreased at the expense of lowering the AP capacity and the rate of RR (Table 1).

Thus, the purpose of our subsequent experiments was to answer the question, how much time is required to completely recover the respiratory activity of the mitochondria isolated from the stressed plants, particularly the NAD-dependent oxidation of substrates catalyzed by complex I. The increase in the rate of malate oxidation in state 3 was observed only after $3 \mathrm{~d}$ of recovery after dehydration and especially after combined stress (Table 1). In this case, malate oxidation was sensitive to rotenone, an inhibitor of complex I of the ETC (data not shown), and was more than by $90 \%$ inhibited by cyanide, i.e., with participation of cytochrome $c$ oxidase of the CP (Table 1). As follows from Fig. 1, the RC ratio was elevated upon oxidation of

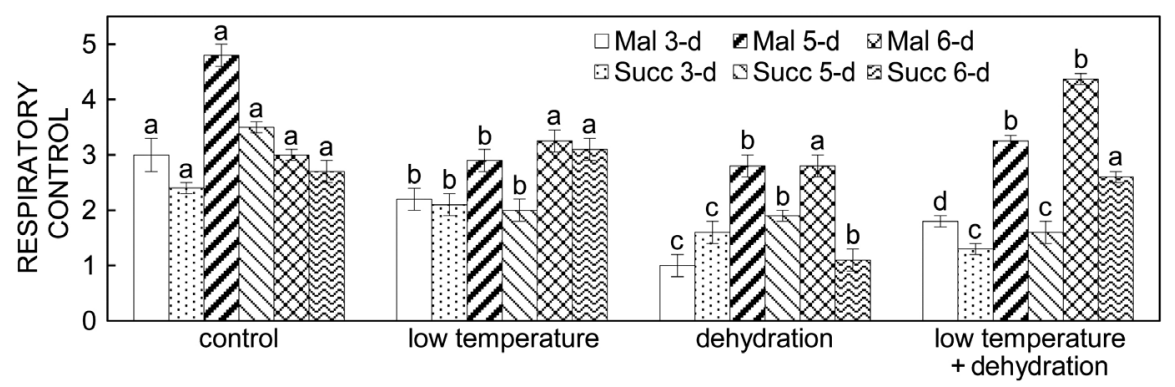

Fig. 1. The respiratory control (RC) of pea seedling mitochondria oxidizing malate or succinate after 3-d growth of seedlings under control conditions (control) and immediately after treatments (Mal 3-d, Succ 3-d), after 2 d (Mal 5-d, Succ 5-d) or 3 d (Mal 6-d, Succ 6-d) of recovery under control conditions. A reaction medium was supplemented with $10 \mathrm{mM}$ malate or succinate, $10 \mathrm{mM}$ glutamate, and $200 \mu \mathrm{M}$ ADP. Means \pm SDs, $n=3$. Different letters indicate significant differences at $P<0.05$ according to the LSD test. 
the given substrate as well, providing evidence for full recovery of adenylate regulation of mitochondrial respiration. Thus, oxidation of malate, catalyzed by complex I, appeared to be more sensitive to the action of the stresses than succinate oxidation catalyzed by complex II. In addition, the rate of malate oxidation in state 3 was completely restored only during recovery from combined stress.

The results obtained show that the observed changes in plant energy metabolism under stresses and during post-stress recovery correlated with the rate of seedling growth and the changes in relative water content in their tissues.

During the first $3-5 \mathrm{~d}$, the number of epicotyl cells increased together with transition from the division state to the elongation one (Havkin 1977). Therefore, the control seedlings exhibited a considerable increase in length after $5 \mathrm{~d}$ (Fig. 2A), whereas the water deficit of epicotyl tissues markedly decreased (Fig. $2 B$ ). Our results indicate that all treatments inhibited epicotyl growth. After one day of dehydration and the combined stress, the epicotyl was shorter than that of the control seedlings and seedlings affected by the low temperature (Fig. 2B). After $2 \mathrm{~d}$ of recovery, epicotyl growth increased, but the rate of the process was different (Fig. 2A). The length of the control seedlings increased 3.3 times during this time interval, but after the low temperature and dehydration, it increased 4 and 7 times, respectively, and 4 times after combined stress. As a result, $2 \mathrm{~d}$ after the low temperature, dehydration, and combined stress, the epicotyl length appeared to be 40, 33, $22.6 \%$, respectively, of that of the control. On the third day of recovery, the rate of epicotyl growth further increased. Nevertheless, the epicotyl length did not return to the control values after the action of either of the factors employed. At the same time, the water deficit of epicotyl tissues considerably decreased approaching control values on day 6 (Fig. $2 B$ ).

We also studied lipid peroxidation in the tissues of pea seedlings by measuring the MDA content. The amount of MDA in seedling tissues after low temperature and combined stress remained similar as in the control plants, MDA content elevated due to dehydration (Table 2). During the course of recovery, the MDA content did not decrease, as expected, but it was elevated. In addition, lipid peroxidation increased not only after dehydration but also after other treatments (Table 2).

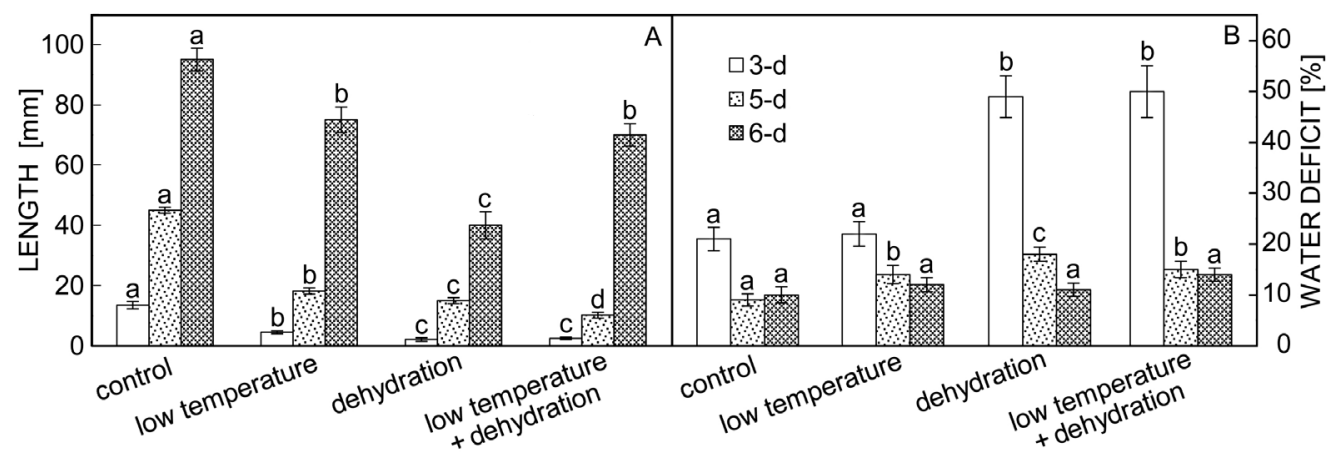

Fig. 2. The length $(A)$ and water deficit $(B)$ of pea seedling epicotyls from controls or at the 0 -d, 2-d, and 3-d of recovery under control conditions after 1-d treatment with a low temperature of $15{ }^{\circ} \mathrm{C}$, dehydration, and combined stress applied to 2-d-old seedlings (final age 3-d, 5-d, and 6-d). Means \pm SDs, $n=100$ (the length) and 10 (water deficit). Different letters indicate significant differences at $P<0.05$ according to the LSD test.

Table 2. Malondialdehyde content [nmol g-1(d.m.)] in epicotyl tissues of pea seedlings immediately after the one-day action of treatments and in the course of their post-stressed recovery under control conditions. Means \pm SDs, $n=3$. Different letters within the same row indicate significant differences at $P<0.05$ according to the LSD test.

\begin{tabular}{lcccc}
\hline Recovery & Control & Low temperature & Dehydration & Combined stress \\
\hline $0 \mathrm{~d}$ & $432 \pm 33 \mathrm{a}$ & $419 \pm 14 \mathrm{a}$ & $650 \pm 39 \mathrm{~b}$ & $382 \pm 15 \mathrm{c}$ \\
$2-\mathrm{d}$ & $505 \pm 27 \mathrm{a}$ & $761 \pm 28 \mathrm{~b}$ & $741 \pm 25 \mathrm{~b}$ & $654 \pm 14 \mathrm{c}$ \\
$3-\mathrm{d}$ & $708 \pm 49 \mathrm{a}$ & $1051 \pm 44 \mathrm{~b}$ & $575 \pm 31 \mathrm{c}$ & $644 \pm 13 \mathrm{~d}$ \\
\hline
\end{tabular}

Our results show that a marked inhibition of epicotyl growth under stress conditions was accompanied by a pronounced inhibition of the capacity of energyproducing $\mathrm{CP}$ in mitochondria isolated from seedlings subjected to dehydration or combined action with the low temperature. Simultaneously, activation of the alternative non-proton pumping pathway in the ETC catalyzed by AOX was observed (Table 1). Analogous results have been described in literature, and different possible explanations of changes in the $\mathrm{CP}$ and AP capacity or 
activity and in the AOX protein content in plant mitochondria under the action of different stress-factors have been discussed (Vanlerberghe and McIntosh 1992, Fiorani et al. 2005, Ribas-Carbo et al. 2005, Generozova et al. 2009, Van Aken et al. 2009, Wang et al. 2011). For example, Fiorani et al. (2005) found that Arabidopsis plants grown at $12{ }^{\circ} \mathrm{C}$ have a higher AOX protein content than control plants and that growth at a low temperature is compromised in plants lacking AP. Also, a number of studies using an oxygen isotope discrimination technique have shown a dramatic decline in CP and increase in AP activity in vivo in response of plants to cold treatment or water stress (González-Meler et al. 1999, Ribas-Carbo et al. 2005, Armstrong et al. 2008). Thus, the results obtained in the first part of our investigation confirm that mitochondria respond to different stresses.

One of widely accepted hypotheses for the physiological role of AP is that AOX can act for reducing excessive generation of ROS by mitochondrial ETC under adverse environmental conditions and for preventing oxidative stress development (Maxwell et al. 1999, Möller 2001, Clifton et al. 2005, Van Aken et al. 2009). It is well known that MDA accumulation can serve as an indirect indicator of membrane lipid peroxidation due to ROS accumulation, and this influences the activity of membrane-localized enzymes including the activity of electron transport chain complexes (Paradies et al. 1999 Taylor et al. 2004). However, it was found that the MDA content in epicotyl tissues did not change significantly immediately after low temperature or combined stress, when the activity of the mitochondrial respiratory system was most strongly inhibited (Tables 1 and 2). Thus, our results suggest that the lipid peroxidation was not related to inactivation of mitochondrial respiration under these conditions.

Our results show that after 2-d recovery, the respiratory activity of mitochondria exhibited clear signs of restoration including an increase of $\mathrm{CP} / \mathrm{AP}$ ratio, significant decline in the capacity of the AO pathway and RR abolition (Table 1, Fig. 2A). However, the full recovery of mitochondrial respiratory activity was reflected only in succinate but not in malate oxidation and only after combined stress (Table 1).

In recent years, sound evidence has been presented for a key role of NAD-dependent oxidation, especially of malate, in plant growth and metabolism recovery after exposure to stress conditions (Fromm et al. 2016, Sew et al. 2016), as well as in preventing changes in the respiratory chain related to senescence (Priault et al. 2007). Jia et al (2016) showed that J-protein (AtDjB1), localized in mitochondrial complex I, is involved in the regulation of plant growth and development through ROS-mediated auxin signalling in Arabidopsis. In addition, we found that a stress-induced modifications of structure of mitochondrial membranes, namely a change in their fatty acid saturation under cold and drought, correlate with the observed changes in the functional activity of these organelles caused by malate oxidation inhibition (Zhigacheva et al. 2011, 2013). Here, an elevation in the rate of malate oxidation in the presence of ADP (state 3) was observed only after 3-d recovery, especially after the combined stress (Table 1). This result is in accordance with data showing that a combination of different stresses results in a different response than individual stresses (Giraud et al. 2008, Zandalinas et al. 2018).

On the third day of recovery epicotyl length after the combined stress became equal to epicotyls after a lowtemperature stress though for the second day the first lagged behind the second. The finding that accelerating seedlings growth observed after combined stress was accompanied by an almost full recovery of the respiratory activity of mitochondria (Fig. 2A) deserves special attention.

We do not know what factors determine the higher sensitivity of NAD-dependent substrate oxidation to stresses compared to succinate oxidation. This may be associated with the modification of the lipid composition of mitochondrial membranes under stress conditions (Zhigacheva et al. 2011). As noted above, the results obtained indicate the absence of any correlation between the membrane lipid peroxidation level and the extent of inhibition of respiratory activity immediately after treatments. This finding may imply that osmotic stress but not oxidative stress is capable of modifying the properties of the inner mitochondrial membrane, and it is the main reason for electron transfer inhibition of the ETC (Mathai et al. 1993, Shugaev et al. 2008, Generosova et al. 2009).

At the same time, this does not exclude that an important determinant of different resistance of complexes of the ETC to the action of the stresses is their different sensitivity to ROS. Further, a high sensitivity of complex I was shown by Pobezhimova et al. (1997), Downs and Heckathorn (1998), and Sweetlove et al. (2002). A higher sensitivity of complex I to ROS compared to complex II (succinate dehydro-genase) may explain the observed phenomenon. Additionally, the literature data indicate that in Zea mays plants subjected to abiotic stress (salinity, $\mathrm{NaCl}$ ), the proper protection of complexes I and II is based on the action of different mechanisms. They show, that in protection of complex I the main role was played by antioxidants (an ascorbate and glutathione), and antioxidant enzymes (a catalase and SOD), whereas the activity of a complex II was maintained by only low-molecular osmoprotectors (Hamilton and Heckathorn 2001). However, additional studies are required to solve this problem.

In agreement to our results, the MDA content is not changed significantly in the leaves of drought-treated plants, but it is elevated during recovery in wheat plants (Simova-Stoilova et al. 2008). These results can demonstrate a decrease of antioxidant protection during the post-stress period. Studies of MDA and hydrogen 
peroxide content, antioxidant system of wheat leaves and proline content allowed authors to conclude that during the period of recovery from severe drought stress on cell membranes increased oxidative strain develops rather than strict control of ROS formation. In addition, it was shown that watering plants after dehydration can induce an additional oxidative stress (Mittler and Zilinskas 1994, Flexas et al. 2006). Wang and Vanlerberghe (2013a) in experiments with transgenic plants with suppressed AOX capacity and decreased amount of this protein also concluded that oxidative stress can increase after rewatering because many antioxidants cease to operate at the end of stress. In our case we noted that during recovering period, against the background of increase in the activity of succinate dehydrogenase, which is one of points of ROS production in the mitochondria (Belt et al. 2017), the capacity of an AOX sharply decreased (Table 1), which has a protective antioxidant function (Valenberghe et al. 2013).

In addition, Foyer and Noctor (2005) proposed that the oxidative stress would be more usefully described as "oxidative signaling", that is, an important and critical mechanism by which plant cells sense the environment and make appropriate adjustments to gene expression, metabolism, and physiology. In this way, it is possible to interpret the increase in MDA content during recovery when plants begin to suffer from lack of light as a need for the increased mobilization of all protective forces for survival. However, of course, this attracted hypothesis requires experimental testing.

\section{References}

Ainsworth, E.A., Rogers, A., Leakey, A.D.B.: Targets for crop biotechnology in a future high- $\mathrm{CO}_{2}$ and high- $\mathrm{O}_{3}$ world. Plant Physiol. 147: 13-19, 2008.

Armstrong, A.F., Badger, M.R., Day, D.A., Barthet, M.M., Smith, P.M.C., Millar, A.H., Whelan, J., Atkin, O.K.: Dynamic changes in the mitochondrial electron transport chain underpinning cold acclimation of leaf respiration. Plant Cell Environ. 31: 1156-1169, 2008.

Atkin, O.K., Macherel, D.: The crucial role of plant mitochondria in orchestrating drought tolerance. - Ann. Bot. 103: 581-597, 2008.

Bandurska, H., Niedziela, J., Chadzinikolau T.: Separate and combined responses to water deficit and UV-B radiation. Plant Sci. 213: 98-105, 2013.

Belt, K., Huang, S., Thatcher, L.F., Casarotto, H., Singh, K.B., Van Aken, O., Millar, A.H.: Salicylic acid dependent plant stress signaling via mitochondrial succinate dehydrogenase. - Plant Physiol. 173: 2029-2040, 2017.

Chance, B., Williams, G.R.: The respiratory chain and oxidative phosphorylation. - Adv. Enzymol. 7: 65-134, 1956.

Clifton, R., Lister, R., Parker, K.L., Sapple, P.G., Elhafez, D., Millar, A.H., Day, D.A., Whelan J.: Stress-induced coexpression of alternative respiratory chain components in Arabidopsis thaliana. - Plant mol. Biol. 58: 193-212, 2005.

Downs, C.A., Heckathorn, S.A.: The mitochondrial small heat-
In summary, pea plant mitochondria are sensitive to even mild changes in environmental conditions, and their responses involve both common changes in the parameters of their respiratory capacity and specific changes characteristic to the type of stress factor. Thus, the elevation in the rate of non-phosphorylating respiration, particularly in the capacity of the AP, as observed in all the variants, displayed a non-specific, adaptive character and was directed to prevent excessive energy accumulation and increased ROS generation by mitochondria due to the inhibition of CP capacity under these conditions. In addition, it was shown for the first time that the restoration of malate and succinate oxidation by mitochondria displayed distinctive differences associated with the nature of the stress factor. The recovery of mitochondrial respiratory activity was mainly due to the inactivation of uncoupled AP and the disappearance of RR. The recovery of the rate of malate oxidation by mitochondria required a more prolonged maintenance of seedlings under control conditions than that of succinate oxidation. The most important finding of this study is that the observed reactivation of malate oxidation by mitochondria along with succinate oxidation occurred only after combined stress, and it correlated with a lower membrane lipid peroxidation than after individual stresses. The maintenance of mitochondrial respiratory activity associated with a significant elevation in the substrate oxidation rate due to functioning complexes I and II of the ETC evidently contributed to recovery of seedling growth.

shock protein protects NADH: ubiquinone oxidoreductase of the electro transport chain during heat stress in plants. FEBS Lett. 430: 246-250, 1998.

Fiorani, F., Umbach, A.L., Siedow, J.N.: The alternative oxidase of plant mitochondria is involved in the acclimation of shoot growth at low temperature. A study of Arabidopsis AOX1a transgenic plants. - Plant Physiol. 139: 1795-1805, 2005.

Flexas, J., Bota, J., Galm'es???, J., Medrano, H., Ribas-Carbo, M.: Keeping a positive carbon balance under adverse conditions: responses of photosynthesis and respiration to water stress. - Physiol. Plant. 127: 343-352, 2006.

Foyer, C.H., Noctor, G.: Oxidant and antioxidant signaling in plants: a re-evaluation of the concept of oxidative stress in a physiological context. - Plant Cell Environ. 28: 1056-1071, 2005.

Fromm, S., Senkler, J., Eubel, H., Peterhänsel, H., Braun, H.P.: Life without complex I: proteome analyses of an Arabidopsis mutant lacking the mitochondrial NADH dehydrogenase complex. - J. exp. Bot. 67: 3079-3093, 2016.

Garnier, E., Shipley, B., Roumet, C., Laurent, G.: A standardized protocol for the determination of specific leaf area and leaf dry matter content. - Funct. Ecol. 15: 688-695, 2001.

Generozova, I.P, Maevskaya, S.N., Shugaev, A.G.: The 
inhibition of mitochondrial metabolic activity in etiolated pea seedlings under water stress. - Russ. J. Plant Physiol. 56: 38-44, 2009.

Giraud, E., Ho, L.H.M., Clifton, R., Carroll, A., Estavillo, G., Tan, Y.F., Howell, K.A., Ivanova, A., Pogson, B.J., Millar, A.H., Whelan, J.: The absence of alternative oxidase1a in Arabidopsis results in acute sensitivity to combined light and drought stress. - Plant Physiol. 147: 595-610, 2008.

González-Meler, M.A., Ribas-Carbo, M., Giles, L., Siedov, I.N. The effect of growth and measurement temperature on the activity of the alternative respiratory pathway. - Plant Physiol. 120: 765-772, 1999.

Hamilton, E. W., Heckathorn, S. A.: Mitochondrial adaptations to $\mathrm{NaCl}$. Complex I is protected by anti-oxidants and small heat shock proteins, whereas complex II is protected by proline and betaine. - Plant Physiol. 126: 1266-1274, 2001.

Havkin, E.E.: Formirovanie Metabolicheskikh System v Rastuschikh Kletkakh Rastenii. [Formation of metabolic systems in growing plant cells]. - Nauka, Novosibirsk 1977. [In Russ].

Hill, S.A., Grof, C.P.L., Bryce, J.H., Leaver C.J.: Regulation of mitochondrial function and biogenesis in cucumber (Cucumis sativus L.) cotyledons during early seedling growth. - Plant Physiol. 99: 60-66, 1992.

Hodges, D.M., DeLong, J.M., Forney, C.F., Prange, R.K.: Improving the thiobarbituric acid-reactive-substances assay for estimating lipid peroxidation in plant tissues containing anthocyanin and other interfering compounds. - Planta 207: 604-611, 1999

Huang, S., Van Aken, O., Schwarzländer, M., Belt, K., Millar, A.H.: The roles of mitochondrial reactive oxygen species in cellular signalling and stress response in plants. - Plant Physiol. 171: 1551-1559, 2016.

Jia, N., Lv, M.X., Wei, S.S., Li, Y.Y., Zhao, C.L., Li, B.: The Jprotein $\mathrm{AtDjBl}$ is required for mitochondrial complex I activity and regulates growth and development through ROS-mediated auxin signalling. - J. exp. Bot. 67: 34813496, 2016

Kuznetsov, V.V.: [General systems of stability and stress signal transduction upon plant adaptation to abiotic stresses] Vestnik Nizhegorod. Univ. 2001: 65-70, 2001. [In Russ.].

Lowry, O.H., Rosebrough, N.J., Farr A.L., Randall R.J.: Protein measurement with the Folin phenol reagent. - J. biol. Chem. 193: 265-275, 1951.

Mathai, J.C., Sauna, Z.E., John, O., Sitaramam, V.: Ratelimiting step in electron transport. Osmotically sensitive diffusion of quinones through voids in the bilayer. - J. biol. Chem. 268: 15442-15454, 1993.

Maxwell, D.P., Wang, Y., McIntosh, L. The alternative oxidase lowers mitochondrial reactive oxygen production in plant cells. - Proc. Nat. Acad. Sci. USA. 96: 8271-8276, 1999.

Mc Donald, A.E., Sieger, S.M., Vanlerberghe, G.C.: Methods and approaches to study plant mitochondrial oxidase. Physiol. Plant. 116: 135-143, 2002.

Mittler, R.: Abiotic stress, the field environment and stress combination. - Trends Plant Sci. 11: 15-19, 2008.

Mittler, R., Zilinskas, B.A. Regulation of pea cytosolic ascorbate peroxidase and other antioxidant enzymes during the progression of drought stress and following recovery from drought. - Plant J. 5: 397-405, 1994.

Möller, I.M. Plant mitochondria and oxidative stress: electron transport, NADPH turnover, and metabolism of reactive oxygen species. - Annu. Rev. Plant Physiol. Plant Mol. Biol.
52: 561-591, 2001.

Møller, I. M., Gardeström, P.: Plant mitochondria - more active than ever! - Physiol. Plant. 129: 1-5, 2007.

Paradies, G., Petrosillo, G., Pistolese, M., Di Venosa, N., Serena, D., Ruggiero, F.M.: Lipid peroxidation and alterations to oxidative metabolism in mitochondria isolated from rat heart subjected to ischemia and reperfusion. - Free Radical. Biol. Med. 27: 42-50, 1999.

Pobezhimova, T.P., Voinicov, V.K., Varakina N.N.: Thermotolerance and functional stability of particular complexes of the respiratory chain in maize mitochondria incubated in vitro. - Russ. J. Plant Physiol. 44: 873-878, 1997.

Priault, P., Vidal, G., De Paepe, R., Ribas-Carbo, M.: Leaf-age related changes in respiratory pathways are dependent on Complex I activity in Nicotiana sylvestris. - Physiol. Plant. 129: 152-162, 2007.

Prasch, C.M., Sonnewald, U.: Signaling events in plants: stress factors in combination change the picture. - Environ. exp. Bot. 114: 4-14, 2015.

Rasmussen, S., Barah, P., Suarez-Rodriguez, C.M., Bressendorff, S., Friis, P., Costantino, P., Bones, A.M., Nielsen, H.B., Mundy, J.: Transcriptome responses to combinations of stresses in Arabidopsis. - Plant Physiol. 161: 1783-1794, 2013.

Ribas-Carbo, M., Taylor, N.L., Giles, L., Busquets, S., Finnegan, P.M., Day, D.A., Lambers, H., Medrano, H., Berry, J.A,. Flexas, J.: Effects of water stress on respiration in soybean leaves. - Plant Physiol. 139: 466-473, 2005.

Rivero, R.M., Mestre, T.C., Mittler, R., Rubio, F., GarciaSanches, F., Martines, V. The combined effect of salinity and heat reveals a specific physiological, biochemical and molecular response in tomato plants. - Plant Cell Environm. 37: 1059-1073, 2014.

Rizhsky L., Liang H., Shuman J., Shulaev V., Davletova S., Mittler R.: When defense pathways collide. The response of Arabidopsis to a combination of drought and heat stress. Plant Physiol. 134: 1683-1696, 2004.

Schmitt, N., Dizengremel, P.: Effect of osmotic stress on mitochondria isolated from etiolated mung bean and sorghum seedlings. - Plant Physiol. Biochem. 27: 17-26, 1989.

Sew, Y.S., Ströher, E., Fenske, R., Millar, A.H.: Loss of mitochondrial malate dehydrogenase activity alters seed metabolism impairing seed maturation and postgerminational growth in Arabidopsis. - Plant Physiol. 171: 849-863, 2016.

Sholts, K.F., Ostrovskii, D.N.: [The cell for the amperometric determination of oxygen] - In Kretovich, V.L., Sholts, K.F. (ed.): Metody Sovremennoi Biokhimii. [Current Biochemical methods.] Pp. 52-58. Nauka, Moskva 1975 [In Russ].

Shugaev, A.G., Generozova, I.P., Shugaeva, N.A., Vyskrebentseva, E.I.: Metabolic activity of plant mitochondria in hypertonic sucrose solutions. - Russ. J. Plant Physiol. 55: 338-343, 2008.

Shugaeva, N.A., Vyskrebentseva, E.I., Orekhova, S.O., Shugaev, A.G.: Effect of water deficiency on the respiration of conducting bundles of sugar beet chard. - Russ. J. Plant Physiol. 54: 373-380, 2007.

Simova-Stoilova, L., Demirevska, K., Petrova, T., Tsenov, N., Feller, U.: Antioxidative protection in wheat varieties under severe recoverable drought at seedling stage. - Plant Soil 
Environ. 54: 529-536, 2008

Song, S.-Q., Tian, M.-H., Kan, J., Cheng, H.-Y.: The response difference of mitochondria in recalcitrant Antiaris taxicaria axes and orthodox Zea mays embryos to dehydration injury. - J. integrative Plant Biol. 51: 646-653, 2009.

Stupnikova, I., Benamar, A., Tolletter, D., Grelet, J., Borovskii, G., Dorne, A.-J., Macherel, D.: Pea seed mitochondria are endowed with a remarkable tolerance to extreme physiological temperatures. - Plant Physiol. 140: 326-335, 2006.

Sweetlove, L.J., Heazlewood, J.L., Herald, V., Holtzapffel, R., Day, D.A., Leaver, C.J., Millar, A.H.: The impact of oxidative stress on Arabidopsis mitochondria. - Plant J. 32. 891-904, 2002

Taylor, N.L., Day, D.A., Millar, A.H.: Targets of stress-induced oxidative damage in plant mitochondria and their impact on cell carbon/nitrogen metabolism. - J. exp. Bot. 55: 1-10, 2004.

Van Aken, O., Giraud, E., Clifton, R., Whelan, J.: Alternative oxidase: a target and regulator of stress responses. - Physiol. Plant. 137: 354-361, 2009.

Vanlerberghe, G.C., McIntosh, L.: Lower growth temperature increases alternative pathway capacity and alternative oxidase protein in tobacco. - Plant Physiol. 100: 115-119, 1992.

Vanlerberghe, G.C., McIntosh, L.: Mitochondrial electron transport regulation of nuclear gene expression studies with the alternative oxidase gene of tobacco. - Plant Physiol. 105:
$867-874,1994$

Vanlerberghe, G.C.: Alternative oxidase: a mitochondrial respiratory pathway to maintain metabolic and signaling homeostasis during abiotic and biotic stress in plants. - Int. J. mol. Sci. 14: 6805-6847, 2013.

Wang, J., Rajakulendran, N., Amirsadeghi, S., Vanlerberghe, G.C.: Impact of mitochondrial alternative oxidase expression on the response of Nicotiana tabacum to cold temperature. - Physiol. Plant. 142: 339-351, 2011.

Wang, J., Vanlerberghe, G.C.: A lack of mitochondrial alternative oxidase compromises capacity to recover from severe drought stress. - Physiol. Plant. 149: 461-473, 2013.

Zandalinas S.I., Mittler R., Balfagyn D., Arbona V. GymezCadenas A.: Plant adaptations to the combination of drought and high temperatures. - Physiol. Plant. 162: 2-12, 2018

Zhigacheva, I.V., Misharina, T.A., Terenina, M.B., Krikunova, N.N., Burlakova, E..B., Generozova, I.P., Shugaev, A.G., Fattakhov, S.G., Konovalov, A.I.: Fatty acid composition of mitochondrial membranes of pea seedlings under conditions of insufficient moistening and moderate cooling. - Dok1. Biochem. Biophys. 437: 87-89, 2011.

Zhigacheva, I.V., Burlakova, E.B., Misharina, T.A., Terenina, M.B., Krikunova, N.I., Generozova, I.P., Shugaev, A.G., Fattakhov, S.G.: Fatty acid composition of membrane lipids and energy metabolism in mitochondria of pea seedlings under water deficit. - Russ. J. Plant Physiol. 60: 212-220, 2013. 